\title{
Lightweight skips - factors influencing operational reliability
}

\author{
S Gorzalczynski Wabi Iron \& Steel Corp., Canada
}

\begin{abstract}
Hoisting mine shaft conveyances from great depth demands lightweight conditions at the end of the hoist rope. The tare weight component of the rope-end load must be minimised in order to maximise available payload. A tare weight to payload ratio is used to gain an expectation of skip hoist reliability with ratios ranging from 1:1 (heavy duty) to as large as 2:1 (light duty) existing in many hoisting applications today. Beyond the 2:1 ratio, skips are deemed too light to withstand the forces of loading and rapid travel speeds, while still offering reliability. In deep hoisting applications, the 'holy grail' of ratios would be 3:1, whereby the skip tare weight is one-third of the payload it is able to carry. To achieve this ratio, the tried and true materials of construction and design philosophies associated with these century-old machines must be abandoned. The fact that rope-end load will come at a premium cost cannot be escaped. Ensuring that this high cost burden is comprised predominately of valuable ore will be the challenge.
\end{abstract}

\section{$1 \quad$ Introduction}

In mine hoisting terms, the skip is considered to be part of the rope-end load. From the perspective of the hoist drive, the skip's tare weight is relatively irrelevant as nearly all types of mine hoists operate in a balanced condition whereby two skips are moved by a single hoist drive. When one skip is at the bottom of the wind cycle, the other skip is at the top of the wind cycle (Figure 1). The imbalance in the hoisting system consists of the extended hoist rope weight and the payload in the lower skip. The skip weight itself, is predominately raised by the weight of the upper skip as it is lowered down the shaft - gravity's reward.

So why be concerned with lightening the skip tare weight? In balanced-hoisting at relatively shallow depth $(<1,600 \mathrm{~m})$, relying on one skip to assist the other while still moving acceptable payload, is rather efficient. This efficiency drops away rather quickly as hoisting depths approach 2,000-2,500 $\mathrm{m}$ due to the simple fact that the extended hoist rope, required to connect the subterranean world to the surface, has itself a tare weight. In fact, gravity's force on the hoist rope creates sufficient stress in the rope's material that at $3,500 \mathrm{~m}$, the rope can only support its own weight safely at the point where it leaves the hoist's sheave wheel allowing no provision for a skip or its payload.

Many hoisting specialists have termed hoist rope weight as a curse (Delorme 2004). While the panacea may be a rope constructed of ultra-light synthetic fibres, that development is far from reality for deep hoisting and steel, with its reasonable modulus of elasticity, is the best, most reliable material we currently have for the manufacture of hoist ropes. Should synthetic ropes gain prominence in hoisting applications, ropes of equivalent breaking strength capacities and representing less than $20 \%$ of the weight of conventional steel ropes (Janovsky 1999), could be realised. Until then, the most practical approach to ensuring that a reasonable payload can be lifted from the shaft bottom, is to provide a lightweight skip structure that burdens the hoist rope strength marginally while still being able to withstand the forces associated with payload charging and rapid travel in the shaft compartment.

This paper will attempt to define the limitations imposed on lightweight skips by current design philosophies and provide insight into the forces generated during skip loading/discharging and movement in the shaft. The ultimate goal in production hoisting from depth is to suspend skips with a payload to tare weight ratio that exceeds $1: 3$ while still offering a skip reliability percentage exceeding $85 \%$. 


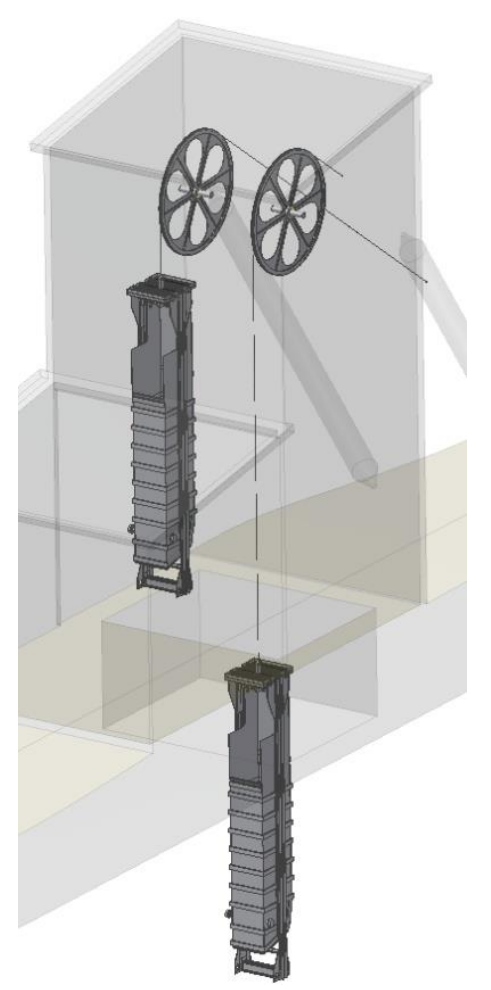

\section{Figure 1 Balanced hoisting}

\section{Design philosophy}

Ore skips are glorified bins. This glorification stems from their dynamic characteristic - payload charging in under 10 seconds, traverse up the shaft at speeds approaching $60 \mathrm{~km} / \mathrm{h}$ followed by rapid payload discharge under motion. And this cycle is repeated in excess of one-hundred times per day continuously for a period approaching 30-40 months. Needless to say, the design of this dynamic bin must offer robust construction, lightweight components and encroach marginally on the available cross-sectional area of the hoisting compartment, i.e. thin-walled bin.

The design concept of skips has remained basically unchanged for the past century. Since the advent of the steam hoist and wire rope, skips have been designed with three basic components - a load carrying bridle or bail, a payload vessel or bucket and a discharge gate or floor. While modern manufacturing techniques have permitted a more sophisticated-looking skip to be offered to the mining industry, its mode of operation is that of the first skips manufactured by Wabi, E. Long or C.S. Card at the onset of the 20th Century. The reason for this stagnancy is due to the straight-forward requirement of this piece of equipment, namely, vertical material conveying. Not unlike the iconic bulldozer, the development of its design realised reliability early and the impetus for change was unnecessary.

Two types of skip designs remain popular in the industry today, namely:

- Bail-type units.

- Uni-body units.

The different design features discussed in Sections 2.1 and 2.2 are identified in Table 1. 
Table 1 Operational parameters - comparison between designs

\begin{tabular}{c|cc}
\hline Skip design feature & Bail-type skip design & Uni-body skip design \\
\hline $\begin{array}{c}\text { Efficient use of shaft compartment } \\
\text { cross-sectional area. }\end{array}$ & No & Yes \\
$\begin{array}{c}\text { Overall length of equivalent volumetric } \\
\text { capacity skips. }\end{array}$ & Longer & Shorter \\
$\begin{array}{c}\text { Tare weight of similar sized skips. } \\
\text { Vertical headroom required to } \\
\text { discharge skips with fixed scroll plates. } \\
\begin{array}{c}\text { Potential for payload bridging in long } \\
\text { slender buckets. }\end{array}\end{array}$ & Heavier & Lighter \\
Operability in rough shaft \\
compartments.
\end{tabular}

\subsection{Bail-type skip design}

The most common bail-type design being used is the bottom dump skip (Figure 2). This style of skip is a workhorse in the industry as its reliability is excellent. It is also capable of maintaining this high reliability rating for a wide range of payload capacities.

Bail-type skip designs suspend the payload vessel (bucket) within a bail. The bail serves to guide the bucket in the shaft compartment and generally isolates the mass of the bucket/payload from lateral accelerations imposed by guide joint misalignment in the travel way as the skip is being hoisted in the shaft compartment. As such, the magnitude of rebound forces is greatly reduced and both the skip structure and the shaft compartment furnishings are spared long-term fatigue damage (Galloway \& Tiley 1983). See Figure 3 for a diagrammatic explanation of this mechanism.

Using a bail to suspend the skip bucket is also advantageous for the use of guide roller suspension systems. Since the guide wear shoes (face location) are not constrained by the skip bucket width, large clearances can be incorporated between the shaft compartment guides and the interfacing wear shoes on the skip bail. These large clearances permit the guide roller suspension system to absorb energy from encounters with guide joint misalignment before the wear shoe actually strikes the guide surface. Again, the result is reduced rebound forces being imparted onto the skip structure and shaft furnishings. This type of energy absorbing arrangement is analogous to the long-travel suspension found on off-road racing vehicles.

\subsection{Uni-body type skip design}

The other design philosophy used for skips is uni-body construction (Figure 4). This term is also used in the automotive sector whereby uni-body construction implies that the vehicle's load carrying chassis and passenger compartment body have been unified and are the same component. This is also the case for uni-body skips - the load carrying bail and the payload vessel (bucket) are one of the same. Vertical load transfer into the hoist rope and travel way guiding provisions are incorporated within the walls of the skip bucket. This design approach permits more efficient use of the available cross-sectional area within the 
hoisting compartment providing a net benefit of shorter overall skip length when compared to bail-type skip designs of equivalent volumetric capacity. In most cases, the overall length of equivalent capacity uni-body skips over bail-type units is approximately $10 \%$ shorter.

This perceived benefit is not without cost and in this case, the cost is twofold. First, uni-body skips are much more susceptible to rough shaft conditions as both the skip and payload are accelerated laterally when shaft guide misalignments are encountered. The resulting rebound forces can be quite significant and often, rough shaft conditions manifest into severe shaft damage when uni-body skips are being operated. Generally, hoisting speeds are reduced to control this damage as shaft maintenance crews are rarely given enough time to remedy the impulse condition contributing to the lateral movement of the skip. Guide roller systems and guide wear shoe clearances are mostly inadequate for conveyance stability especially when uni-body skips are manufactured with large capacities.

Herein lies a true irony since the uni-body skip design is often selected for large capacity skips in order to minimise the overall length of the skip.

The second cost associated with this skip design philosophy is that of shaft spillage during the skip discharge cycle. Since the skip has no bail, the bucket cannot be moved outward from the shaft compartment during the dump cycle. It is this outward swing of the bucket that creates positive overlap with the dump chute lip in the hoist plant headframe eliminating the potential for muck spillage down the shaft. As the guiding system is unified with the skip bucket in the uni-body design, the bucket cannot swing into the dump chute since the shaft guides have it captured. Skip discharge must occur over the operating gap between the skip and the dump chute lip permitting fine muck to escape the stream and drop down the shaft.

While the spillage rate is tiny, successive spillage over thousands of skip dump cycles contributes to a very significant shaft maintenance problem. There has been several ingenious devices invented to attempt control of this spillage, however, most of these inventions are marginally successful at best.

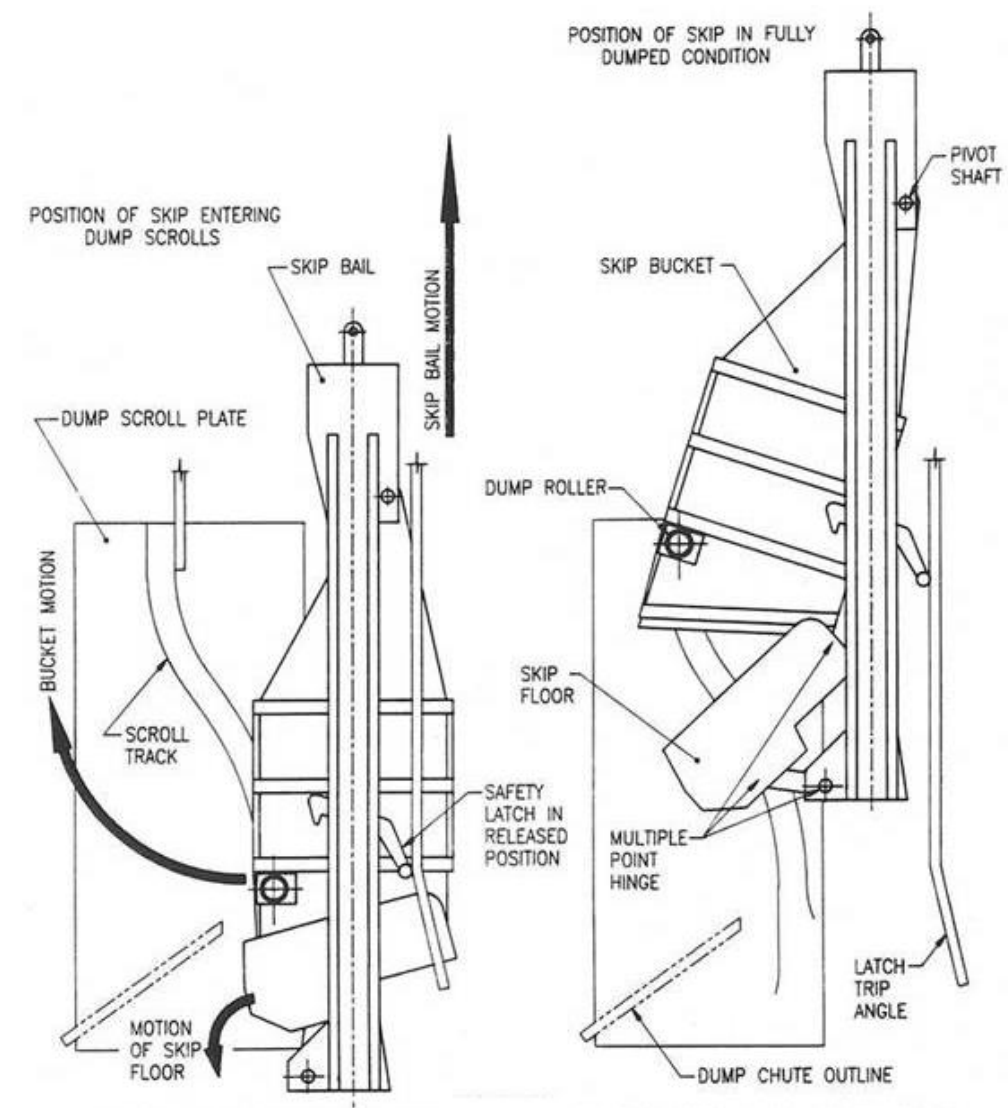

Figure 2 Bail-type skip 


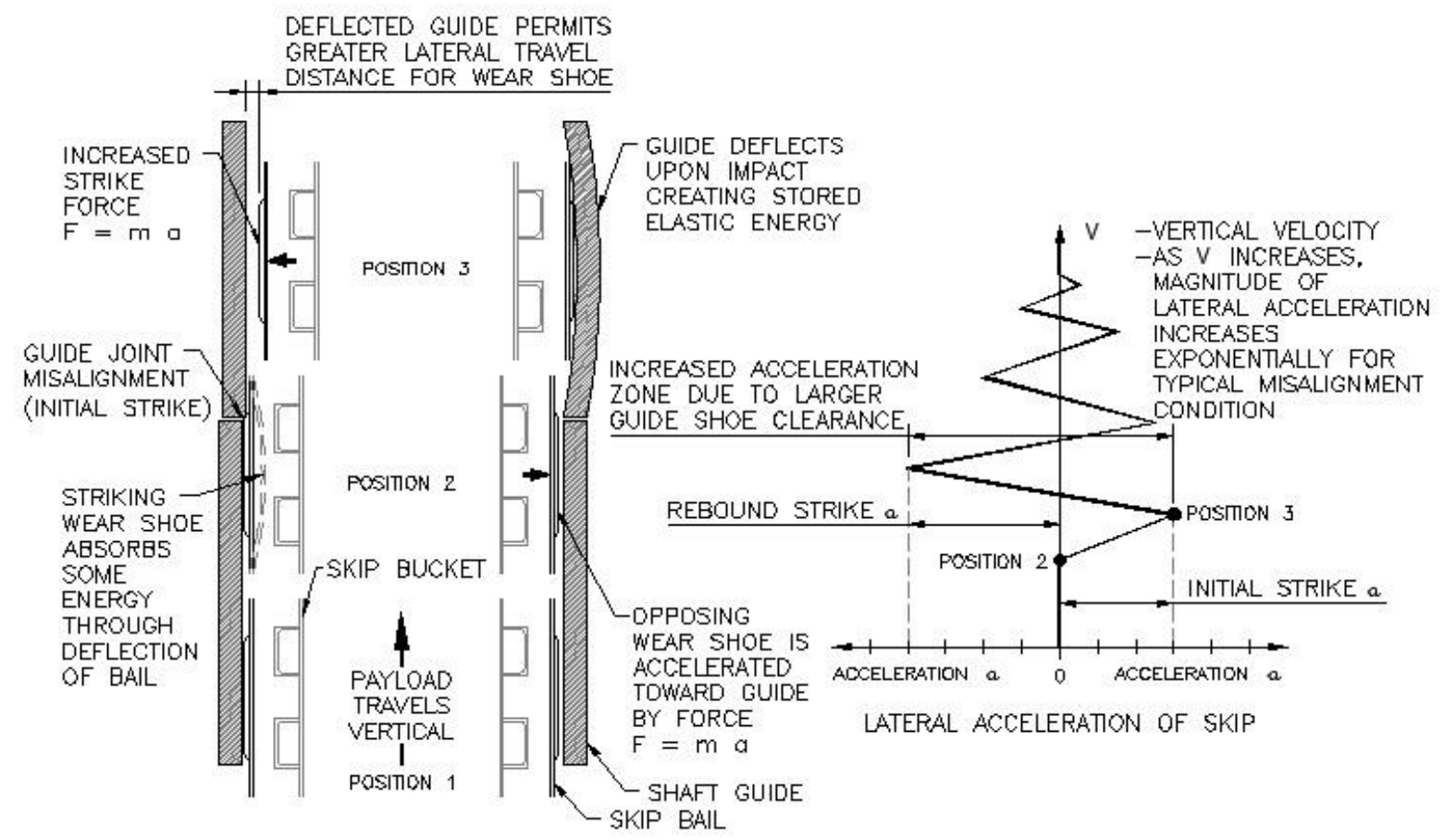

Figure 3 Lateral acceleration of skip due to guide misalignment

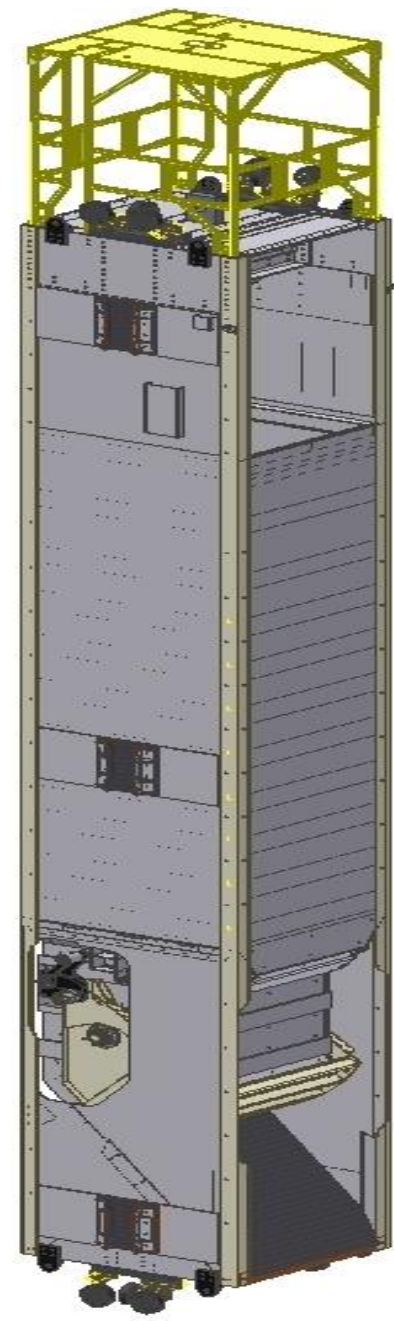

Figure 4 Uni-body skip 


\section{Tare weight}

Tare weight or empty weight is the final weight of all the components assembled into a complete skip. This weight represents the necessary parts required to capture the payload from the skip loading station, transport that payload up the mine shaft and discharge the payload into the headframe dump chute. In deep hoisting applications, it is this tare weight that the manufacturer tries to minimise while still offering a machine capable of reliably moving payload up the mine shaft. Regardless of design philosophy employed in the skip's construction, the composition of this tare weight is comprised of the following critical component categories:

- Load carrying members.

- Dump motion activating members.

- Payload vessel shell.

- Wear liners.

- Safety devices.

- Travel guidance systems.

Table 2 provides the tare weight breakdown as a percentage pertaining to these critical component categories for equivalent volumetric capacity skips manufactured from either design philosophy.

With both types of skip construction, the two component categories representing the majority of conveyance tare weight are load carrying members and the payload vessel. Again, with both skip designs, the majority of mass for load carrying members is found in the longitudinal members connecting the upper and lower drawhead (transverse) members together. For the payload vessel category, the mass is contained in the body plates of the skip bucket. Due to their large surface area, even small reductions in thickness have a significant impact on this compositional weight component.

Table 2 Tare weight compositional breakdown

\begin{tabular}{c|cc}
\hline Critical component category & Bail-type design & Uni-body design \\
\hline Load carrying members & $43 \%$ & $34 \%$ \\
Dump motion activating & $10 \%$ & $12 \%$ \\
members & $30 \%$ & $36 \%$ \\
Payload vessel shell & $12 \%$ & $14 \%$ \\
Wear liners & $2 \%$ & $1 \%$ \\
Safety devices & $3 \%$ & $3 \%$ \\
Travel guidance system & $100 \%$ & $100 \%$ \\
\hline Tare weight total & &
\end{tabular}

\section{$4 \quad$ Forces/loading on skip structure}

Before a component category can be considered for lightening, the different modes of loading on the skip structure must be understood. A skip is a vertical structure that is held under tension by the force of gravity. The longitudinal members are maintained between maximum and minimum tensile stress states over the hoisting cycle. Skip charging and acceleration out of the loading station constitute the largest dynamic load fluctuations in the skip structure under normal hoisting conditions (Borello et al. 1996). Under these conditions, the fatigue life of both axially and transversely loaded members would be substantial, however, this is never the condition in actual mine shaft compartments. 
Under normal conditions, the skip structure is subjected to loading from the following sources:

- Skip charging at the loading station chute.

- Acceleration to full hoisting speed.

- Deceleration to creep speed in the headframe dump area.

- Skip discharge via dump scroll tracks.

During these events, both transverse and longitudinal members are maintained in a tensile stress state. Member deflections are generally well understood from these loading events and little concern exists for stress concentrations that would otherwise reduce the fatigue life of the construction materials. Aside from normal hoisting conditions, several other loading inputs exist that cause high stress conditions not specifically considered in the skip design, namely:

- Misaligned shaft guide joints.

- Misaligned guide strings.

- Hoist rope oscillations and rope torque.

- Corrosion pitting of construction materials.

- Emergency hoist stops and inadvertent safety mechanism application.

- Eccentric payload placement.

- Overtravel arrestor engagement in shaft end zones.

Under general circumstances, these loading conditions are satisfied in the skip design calculations through the application of relatively substantial factors of safety on the design loading condition (Ontario Ministry of Labour 2010). Based on the currently accepted weight to payload ratios and construction materials, this design methodology will continue to produce reliable skip designs. However, as lightening measures are considered and/or non-conventional construction materials are incorporated, these unforeseen events must be better understood from the standpoint of force-input magnitude and mode of force application. This is a critical step in achieving a new light duty threshold for skips offering a 3:1 weight to payload ratio.

The following discussion outlines the conditions encountered during a normal hoisting cycle. When these conditions are well addressed in the skip design, the path forward becomes clearer when dealing with unforeseen events.

\subsection{Skip charging}

Regardless of skip design being charged, the force distribution is similar. Provided the skip is not chaired during this operation, the skip structure remains in tension. In this state, both the skip structure and the hoist rope are subjected to a large impact force as the duration of load transfer from the skip loading station to the skip lasts only several seconds. As such, one can safely assume an impulse force magnitude of payload $\times 0.25$ for the initial impact in the empty skip bucket. It is this impact force that can easily cause the hoist rope to stretch twice its final static stretch amount induced by the skip payload. While the strain on the hoist rope is significant, the skip structure actually benefits from the rope's elastic behaviour. The rope's spring-like behaviour serves to dampen this impact energy on the skip floor significantly. Load transfer efficiency suffers as the lunging skip bucket loading lip permits significant fines leakage down the shaft.

The payload vessel (skip bucket) consists of approximately one-third of the skip tare weight (Table 2). Lightening of this component is usually considered through reductions in body pate thickness and while this approach is very efficient in weight reduction, deflections of the bucket body panels must be considered. Figure 5 outlines three common areas of deflection with bail-type skip designs during charging 
operations. Control of the magnitude of the deflection in these areas is critical as excessive deflection generally leads to cracked seam welds and stiffener attachment welds.

The design of the skip loading station discharge gate and chute can significantly alter the magnitude of loading impact forces both, beneficially or adversely depending on the path chosen by the designer.

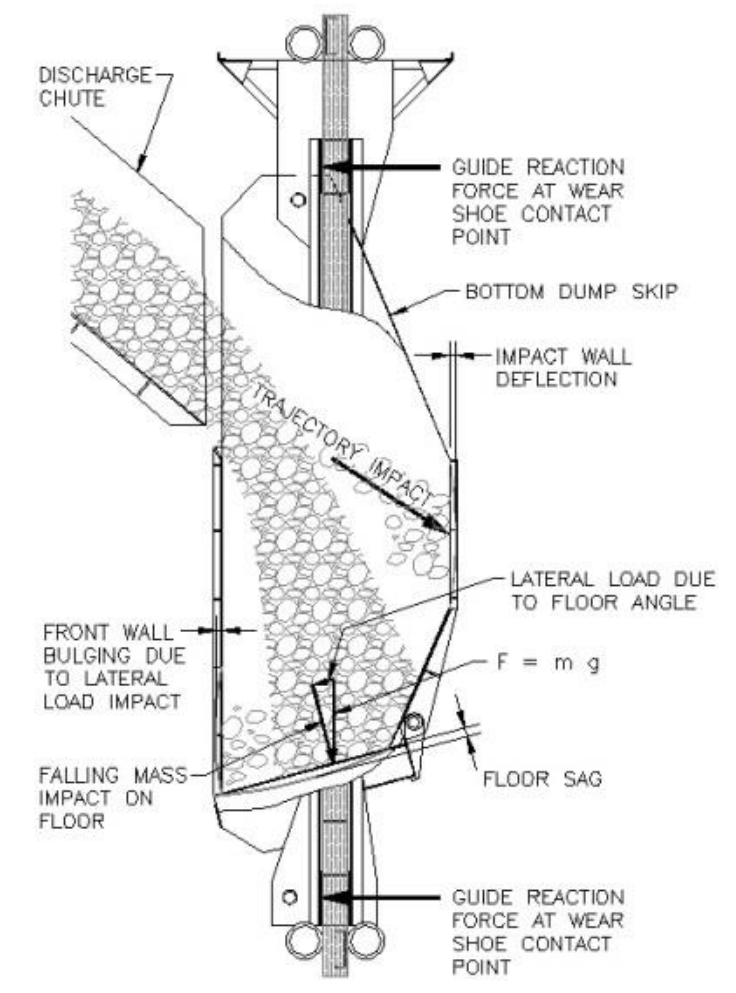

Figure 5 Skip charging forces

Often, skip chairing is used to control the dynamic forces in the hoist rope and the degree of leakage during skip loading (Figure 6).

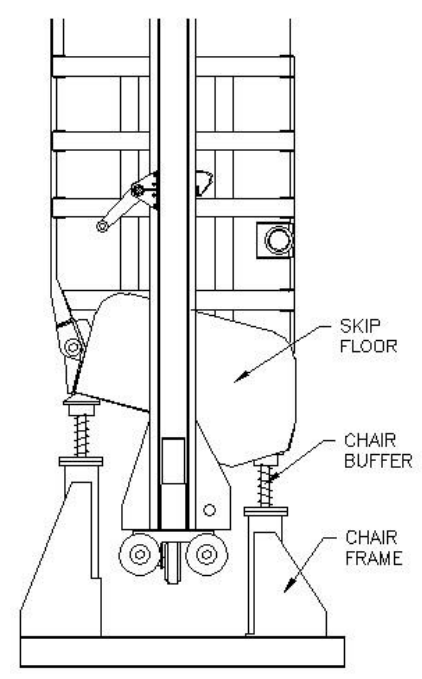

\section{Figure 6 Skip chairing}

Chairing a skip is very effective for the control of hoist rope stress and spillage during skip charging, however, chairing also reverses the stress direction in the skip structure from tensile to compressive. This stress reversal significantly shortens the fatigue life of longitudinal members in the skip structure and 
demands that certain physical properties of structural members be designed as large as possible - namely, the radius of gyration for bail members. This condition does not lend itself well to the lightening initiative. Skip holding is a hybrid from of chairing whereby hydraulic clamps grip and hold the skip during charging. The skip structure remains in tension during holding and as such, stress reversal does not occur. Whether the skip is held or chaired, the benefit of the hoist rope's elastic behaviour is lost and significant impact forces are delivered to the skip.

\subsection{Skip discharge}

Bail-type skips and most uni-body skips use fixed dump scroll tracks to initiate skip discharge. These tracks are mounted to the headframe structure and the skip travels into them by interfacing with rollers on the skip. The speed at which this occurs is approximately $0.25 \mathrm{~m} / \mathrm{s}$. The interface between the scroll track opening and the dump roller on the skip requires accurate alignment and this alignment is influenced by the operating clearance between the shaft guide and the skip wear shoes. Wear on either the guide faces or the wear shoe surfaces will decrease the accuracy of this alignment. Under poor alignment conditions, severe impact forces can be imparted into the roller assembly and scroll tracks upon negotiating the skip dump cycle.

The largest force on the skip structure comes from redirecting the discharging muck stream from the bucket into the headframe dump chute. This directional change creates an impact pressure on the skip floor resulting in loads being applied to the compartment guides through reactionary forces at the skip wear shoe points (Figure 7). It is this loading that slowly moves the guide from its theoretical position and affects the alignment requirement between the scroll entry point and the dump roller on the skip. Over time, this guide movement coupled with guide/wear shoe erosion, can lead to grossly misaligned components resulting in significant impact forces at each dump cycle start.

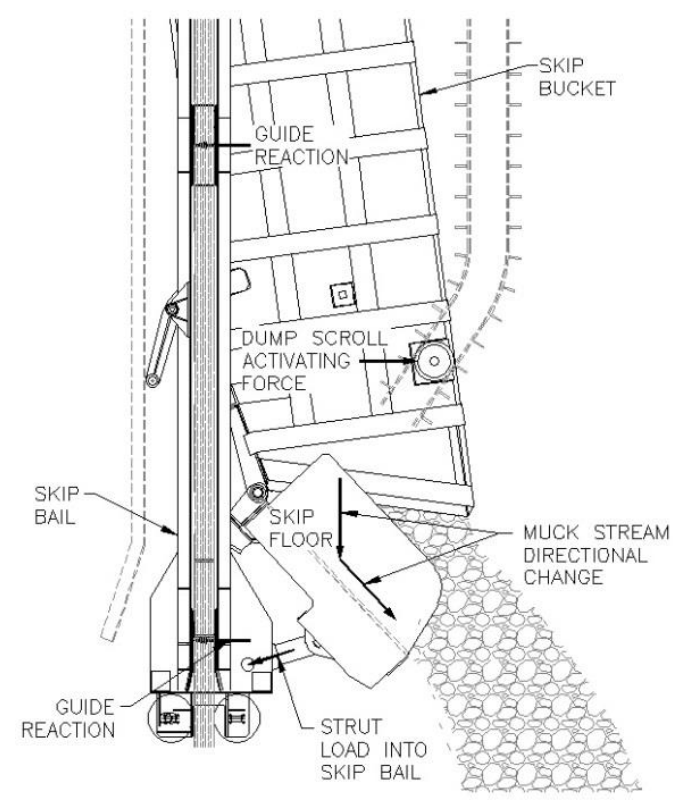

(a)

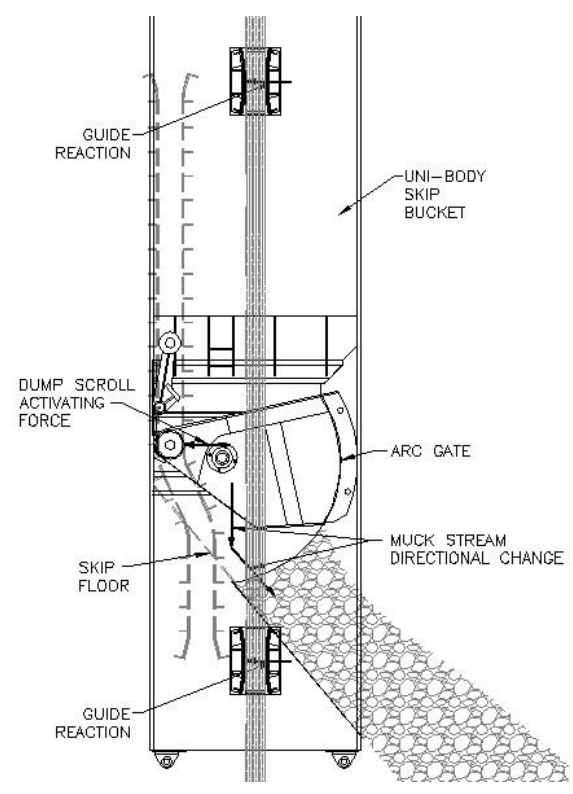

(b)

Figure 7 Skip discharge; (a) bail-type; and (b) uni-body designs

\subsection{Lateral loading}

As previously discussed, lateral loads are generated during vertical travel in the shaft from a number of sources. Lateral loading need not be isolated to pure horizontal impulses as conditions such as rope torque, hoist rope oscillations and eccentric payload placement all lead to non-axial loading conditions. The largest contributor, however, to lateral loading is poorly aligned shaft guide joints. The importance of guide joint alignment cannot be over emphasised as this condition has the ability to influence production rates in the 
mine shaft greater than any other maintenance parameter. Hoisting speed, hoist rope life and conveyance life are all closely linked to the quality of guide joint alignment (Redpath \& Shaver 1977). Figure 8 illustrates the loading for the two designs and the reason why bail-type skips survive much better than uni-body skips in rough shaft conditions.

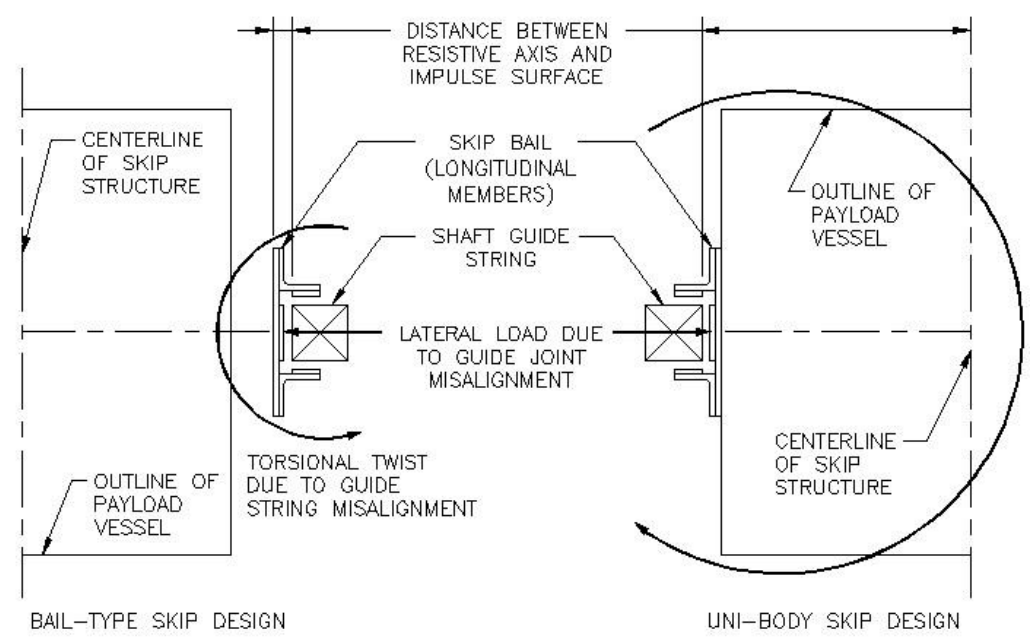

Figure 8 Resistive loading developed from non-axial impulses

The bail-type skip example shown in Figure 8 offers a small radius arm between the impulse surface (shaft guide) and the extreme fibre surface (bail plate) resisting external forces on the bail. This small radius arm permits the bail assembly to flex when lateral loads are applied and in doing so, the main skip structure is spared the loading being imparted onto the skip bail. By deflecting, the bail absorbs a considerable amount of the impulse energy leaving the payload mass relatively static in the lateral plane.

The opposite is true for the uni-body skip design (Figure 8). Since the guide wear shoe brackets are mounted directly to the skip bucket, lateral impulses are resisted by a rather large, rectangular box shape that offers a considerable moment radius arm between the impulse surface and the extreme resisting fibre of the structural shape. As such, the structure is extremely stiff and provides little energy absorption from the lateral impulses. This energy transfers directly to the payload mass under these circumstances resulting in significant rebound forces being generated within the skip structure and shaft furnishings.

Under the conditions outlined in Figure 8, the long term fatigue resistance of the bail-type unit is superior to the uni-body unit since the bail is very effective at payload isolation. While the flexure of the bail assembly does eventually cause material fatigue, the bolted design used in bail assemblies is very durable and offers good fatigue resistance. The uni-body skip design, on the other hand, is a welded structure offering very limited flexibility. The payload vessel (skip bucket) is fastened together with welded connections and under flexural stress conditions, the welded areas behave as locked zones permitting no relative movement. Stress amplification in these zones is very high and the material becomes hyper-sensitive to metallurgical and surficial imperfections. Cracking generally results when the induced loading creates material stresses that exceed the material's yield strength. Crack propagation then becomes rapid and directionally unpredictable.

\section{Conclusions}

Lightening of the skip structure while maintaining traditional materials of construction is the safest way to achieve tare weight reductions at the rope-end load. Given the differences between bail-type and uni-body skips, the advantages of the latter design seem not to outweigh the potential maintenance issues that may present themselves if uni-body skips are lightened beyond their reliable range. The primary disadvantage of the uni-body design when considering the 3:1 weight to payload ratio, is the inability of the design to isolate the payload mass from lateral motion impulses. As deep mine shafts will inherently contain more guide joint connections, the potential escalates for sequential misalignment strikes as the skip moves up 
the shaft leading to the generation of rather significant lateral accelerations $(>1.5 \mathrm{~g})$. Under such circumstance, lightweight bail-type skips would far outperform similar weighted uni-body skips from a reliability standpoint.

Provided the mine shaft compartment provides theoretically normal hoisting conditions, both skip design philosophies are applicable to the lightweight initiative. Load carrying members (bail) and the payload vessel shell (bucket) should be targeted for the majority of tare weight reduction. When thinning members, care must be taken to quantitatively establish values for unforeseen loading inputs as outlined under Section 4.

Lateral loading into the skip structure must be measured accurately in the shaft environment using accelerometer devices at a general location on the skip and using the output from this instrument to calibrate a computer modelling environment for more detailed analysis of skip components when subjected to high lateral impulse forces. In this manner of design change, finite element analysis (FEA) can be very effective at reactive predictions and material stress conditions under a wide range of inputs.

The ability of manufacturers to provide the mining industry with ultra-light skips is possible provided this initiative is met with an understanding by the industry that experimentation exists and design improvements with operating equipment may be required for the initial phases in the development of these skips. The actual mine environment will always produce results substantially harsher than any form of laboratory or computer testing due to the pressures of real-world requirements and the ever present human-interface component. As such, industrial partners willing to tolerate growing pains is an absolute requirement for the realisation of ultra-light skips in deep mining applications.

\section{References}

Borello, M, van Zyl, MN \& Wainwright, EJ 1996, The safe use of mine winding ropes, vol. 3, project no: GAP 054, submitted to Safety in Mines Research Committee (SIMRAC).

Delorme, G 2004, The challenges of hoisting at great depths - the curse of rope weight, Canadian Institute of Mining, Metallurgy and Petroleum, Westmount.

Galloway, LC, \& Tiley, PM 1983, 'The performance of fixed guidance systems in mine shafts', CIM Bulletin, vol. 75, no. 847. Janovsky, L 1999, Elevator Mechanical Design, 3rd edn, Elevator World Publications, Mobile.

Ontario Ministry of Labour 2010, Regulation 854 - Mines and Mining Plants, Section 230(4), Ministry of Labour, Toronto.

Redpath, JS, \& Shaver, WM 1977, 'Toward a better understanding of mine shaft guides', CIM Bulletin, vol. 70, no. 787, pp. 90-100. 
